Inferiority Feelings in the Individual and the Group

By Oliver Brachfeld. Translated from the French by Marjorie Gabain. Pp. 301. (London: Routledge and Kegan Paul, Ltd., 1951.) 25s. net. THIS book was written in Spanish by a translated from the French into English. One might have expected from such metamorphoses that the result would be unintelligible; but so carefully has the translator, Marjorie Gabain, done her work that the text reads as if it had been written directly in English. The book is an attempt to show the historical emergence of Adler's ideas in such precursors as Montaigne, Hobbes, Mandeville, Vauvenargues, and so on, then the views of Adler himself, and finally their application to the individual and to society. The author draws on innumerable sources, both medical and literary, and is obviously widely read in most European languages. Most of the exposition of Adlerian principles merely follows the lines laid down by that school; but it is done in an interesting way. In some cases it is superficial and even contradictory; for example, the author is willing to accept the results of questionnaires regarding the superficial causes of inferiority, but he refuses to accept the fact that few musicians are deaf as a refutation of the Adlerian principle that musical ability is the result of over-compensation, as put forward by Elsa Bienenfeld.

The most interesting and original part of his book is the attempt to apply the theories of individual psychology to such problems as industrial disputes. It is long past time when psychologists should have made studies of the deeper causes of strikes and lock-outs, not from the point of view of benefiting either the employers or the employees, but to prevent them and the consequent disruption of society. A knowledge of the deeper causes of industrial warfare may help to prevent international disputes and the wreckage of society. Attempts, such as the author's, to understand the psychology of national feeling may finally give us a deeper knowledge and lead to prevention of war.

This book is a sound exposition of the Adlerian point of view and will interest those who find Adler's work satisfying. It is excellently produced, the paper is good, the print clear, and the binding in brown with gold lettering unobtrusive.

Clifford Allen

The Electrical Activity of the Nervous System A Textbook for Students. By Dr. Mary A. B. Brazier. Pp. $x+220$. (London: Sir Isaac Pitman and Sons, Ltd., 1951.) 25s.

THIS short text-book gives a useful elementary introduction to the electrophysiology of the central and peripheral nervous system and of the sense organs. Considerable knowledge of anatomy and physiology and some knowledge of elementary physics are required of the reader. The earlier chapters, which deal with the electrical properties and general physiology of peripheral nerve and of the spinal cord, are less detailed and self-contained than are the later ones, in which the peripheral and central sensory apparatus and the spontaneous electrical activity of the brain are described.

In these later chapters, the book ranges rather more widely and goes a little more deeply into its subject-matter than do the relevant sections of the standard texts on physiology. Medical students will find in it interesting supplementary reading. Those embarking on advanced courses in physiology will not need it beyond the early stages of their work in electrophysiology, but they will find the bibliographies useful. The book will be specially valuable to those physicists who are nowadays being attracted into the field of applied electrophysiology. Parts of it would interest general biological and scientific readers.

The writing is admirably clear, the presentation that of a gifted teacher and the many illustrations have been wisely chosen.

\section{The Physics of High Pressure}

By Prof. P. W. Bridgman. (International Text-Books of Exact Science.) New impression, with Supplement. Pp. viii +445. (London: G. Bell and Sons, Ltd., 1949.) 35s. net.

THE main achievements of the past twenty years in the high-pressure field are described in a supplement of some forty pages, which is the chief addition to this new impression of Prof. P. W. Bridgman's standard work. Although this method of revision was probably dictated by the photo. graphic process used, no happier way could have been chosen; for the story of the author's own monumental researches is continued beyond the range of pressures reached in the work of the original volume, up to $100,000 \mathrm{kgm} . / \mathrm{cm} .{ }^{2}$ in many cases, and this is the natural sequence to adopt. A number of new problems, such as the behaviour of metals under shear and plastic deformation at high pressure, are discussed as well as extensions of earlier investigations.

The only alteration in the body of the earlier text is in the section on the compressibility of the alkali metals. In 1931 it had seemed worth while to look for indications of the breakdown of atomic structure under the pressures then attainable. Redetermination of the values, and their extension to the highest pressure range, still fail to reveal any premonition of such breakdown, though in the case of cæsium two interesting discontinuities in the pressure-volume curve are recorded.

Apart from its uncontested authority as the work of reference on this subject, this is a book which the physicist with less-specialist intent can read with profit. It is a story of difficulties sought out and hunted down, written in a style which reveals the author as one of the calmest and most equable of experimenters. His comments and discussion are rich in scientific wisdom, and it is good to see the book once again in print.

Scientific Survey of South-Eastern Scotland

Prepared for the Meeting held in Edinburgh, 8th to 15th August 1951. Pp. 208. (Edinburgh : British Association Local Executive Committee, The University, 1951.) $15 s$.

THIS book was prepared in connexion with the meeting at Edinburgh this year of the British Association for the Advancement of Science, and, on the lines of surveys for other years of the locality around previous meeting-places of the Association, it gives a comprehensive but succinct account of the history, social conditions and economy of south-east Scotland as well as its scientific features, natural and otherwise. The area covered is made up of the counties of Fife, Kinross, West Lothian, Midlothian, East Lothian, Peebles, Berwick, Selkirk and Roxburgh 